\title{
Late Preterm Birth and Growth Failure in Childhood: What do we do now?
}

\author{
GiRiJa NataRAJAN \\ Professor of Pediatrics and Co-Chief, Division of Neonatology, Wayne State University School of Medicine, Detroit, MI, USA. \\ gnatara@med.wayne.edu
}

$\mathrm{I}$ $\mathrm{n}$ the past decade, there has been an increasing recognition that late-preterm ( $34^{0 / 7}$ to $36^{6 / 7}$ weeks) infants are not merely "near-term" infants [1]. A range of neonatal problems, mainly due to immaturity and difficulties in respiratory transition, has been identified in this population. Increased health-care utilization, short-term morbidities and adverse neurodevelopmental outcomes in childhood in latepreterm infants, in comparison to infants born at term, have also been described in a rich body of literature $[1,2]$. What remains unclear is the long-term medical impact of late preterm birth. This knowledge gap is particularly stark for late preterm infants who were relatively well in the neonatal period and discharged home within 48 hours of age.

In this issue of Indian Pediatrics, Gupta and colleagues [3] report the results of a prospective longitudinal cohort follow-up study of 200 late preterm infants and 199 term controls. The participating infants were enrolled from a single center in Northern India, predominantly from the lower socioeconomic class, and details of medical morbidities, mortality and growth measures were collected at 12 months chronological age. The follow-up rate was fair at about $80 \%$. Consistent with previous reports, the late preterm cohort experienced a greater incidence of feeding difficulties, jaundice, fever and diarrheal episodes, and rehospitalization through a year of age. Exclusive breastfeeding was lower and difficulties in latching were reported by care-givers, which could have been the antecedent to the infectious complications during infancy. The striking finding of the study was the 4.1-fold risk of being underweight at 12 months among healthy late preterm infants, after adjustment for maternal weight, gender, socioeconomic status and exclusive breastfeeding. One previous population-based study from Brazil showed an increased risk of being underweight at both 12 and 24 months of age among late preterm infants [4]. The current study [3] confirms growth failure during infancy, but shows a lower rate of weight gain during infancy in late preterm infants. The rate of increase of head circumference was higher than among term controls and length gain was comparable in the two groups; these results may suggest the beginning of catch-up growth. In a recent study [5] in 108 late-preterm individuals, for every standard deviation faster weight and head growth from birth to 5 months and head growth from 5-20 months corrected age, there was a 0.19-0.41 standard deviation increase in IQ at 24-26 years of age. In contrast, rapid catch-up growth is thought to be associated with obesity, adverse lipid profile and chronic diseases in adulthood. In any case, whether the growth failure at 12 months is transient or persists into adulthood, the implications are serious. In a systematic review of studies from low- and middleincome countries [6], undernutrition in childhood was associated with high glucose concentrations and elevated blood pressure in adulthood, after adjustment for adult body mass index and height. The finding of growth failure until 12 months of age in a cohort of well appropriate-forgestational age late preterm neonates, who did not manifest any neonatal signs of immaturity, is sobering.

Another finding of the study by Gupta, et al. [3] was that mortality until 12 months of age was statistically comparable between late preterm infants and their termborn counterparts, although the raw number of late preterm infants who died was more than double the term infants. In a previous study [7] using linked birth and death data in the United States over several years, infant mortality rates in the year 2002 were 3 times higher in late-preterm infants than term infants (7.9 versus 2.4 deaths per 1000 live births); early, late, and post-neonatal rates were 6-, 3-, and 2- times higher, respectively. During infancy, the leading causes of death in late preterm infants were congenital malformations (leading cause), newborn bacterial sepsis, and complications of placenta, cord, and membranes. The current study failed to show a difference in mortality probably due to the limited sample size and exclusion of infants with congenital anomalies. 
So, what do we do with this new information? First, as the authors point out, these data should raise awareness of the unique vulnerability of late preterm infants. They should be treated as high-risk and monitored closely for breastfeeding success, jaundice, nutritional intake and growth, with prompt nutritional intervention, when necessary. The impact of nutritional surveillance and intervention on further outcomes needs to be investigated. Second, pediatricians need to highlight to the public and to our obstetric colleagues that delivery earlier than 39 weeks of gestation carries medical and neurodevelopmental risks that extend into childhood, and possibly, through adulthood. Finally, multiple randomized controlled trials, including 3200 women at $34-36^{6 / 7}$ weeks' gestation and at risk of imminent premature delivery, have shown that infants exposed to antenatal betamethasone had a significantly lower incidence of transient tachypnea of the newborn (RR $0.72,95 \%$ CI 0.56 to 0.92 ), severe respiratory distress syndrome (RR $0.60,95 \% \mathrm{CI} 0.33$ to 0.94 ), and use of surfactant (RR $0.61,95 \%$ CI 0.38 to 0.99 ) [8]. The impact of antenatal betamethasone on growth outcomes, especially in low- and middle-income late preterm populations, needs to be studied.

Funding: None; Competing interests: None stated.

\section{REFERENCES}

1. Raju TN, Higgins RD, Stark AR, Leveno KJ. Optimizing care and outcome for late-preterm (near-term) infants: A summary of the workshop sponsored by the National
Institute of Child Health and Human Development. Pediatrics. 2006;118:1207-14.

2. Cheong JL, Doyle LW, Burnett AC, Lee KJ, Walsh JM, Potter CR, et al. Association between moderate and late preterm birth and neurodevelopment and social-emotional development at age 2 Years. JAMA Pediatr. 2017;171:e164805

3. Gupta P, Mital R, Kumar B, Yadav A, Jain M, Upadhyay A. Physical growth, morbidity profile and mortality among healthy late preterm neonates. Indian Pediatr. 2017;54: 629-34.

4. Santos IS, Matijasevich A, Domingues MR, Barros AJ, Victora CG, Barros FC. Late preterm birth is a risk factor for growth faltering in early childhood: A cohort study. BMC Pediatr. 2009;9:71.

5. Sammallahti S, Heinonen K, Andersson S, Lahti M, Pirkola $\mathrm{S}$, Lahti J, et al. Growth after late-preterm birth and adult cognitive, academic, and mental health outcomes. Pediatr Res. 2017;81:767-74.

6. Victora CG, Adair L, Fall C, Hallal PC, Martorell R, Richter L, et al.; Maternal and Child Undernutrition Study Group. Maternal and child undernutrition: consequences for adult health and human capital. Lancet. 2008;371: 340-57.

7. Tomashek KM, Shapiro-Mendoza CK, Davidoff MJ, Petrini JR. Differences in mortality between late-preterm and term singleton infants in the United States, 1995-2002. J Pediatr. 2007;151:450-6.

8. Saccone G, Berghella V. Antenatal corticosteroids for maturity of term or near term fetuses: systematic review and meta-analysis of randomized controlled trials. BMJ. 2016;355:i5044. 